\title{
ASEAN Class Program di MTs. Muhammadiyah 1 Malang
}

\author{
Najamuddin Khairur Rijal ${ }^{*}$, Haryo Prasodjo², Devita Prinanda ${ }^{3}$ \\ 1,2,3 Program Studi Hubungan Internasional, Fakultas Ilmu Sosial dan Ilmu Politik, Universitas Muhammadiyah Malang, Jawa Timur
}

\section{A R T I C L E I N F O}

Article history:

Received 10 February 2020

Received in revised form

25 March 2020

Accepted 30 April 2020

Available online 28 May 2020

Kata Kunci:

ASEAN, Masyarakat ASEAN,

kesadaran ber-ASEAN

Keywords:

ASEAN, ASEAN Community, ASEAN We Feeling.

\begin{abstract}
A B S T R A K
Program pengabdian ini diarahkan pada upaya memberikan bekal pengetahuan kepada siswa/siswi MTs. Muhammadiyah 1 Malang tentang ASEAN dan Masyarakat ASEAN (ASEAN Community). Hal itu didasarkan pada permasalahan minimnya informasi bagi siswa tentang ASEAN karena keterbatasan bahan belajar dan informasi tentang ASEAN hanya menjadi sub bahasan pada mata pelajaran. Selain itu, pihak sekolah memandang pentingnya wawasan internasional untuk mewujudkan visi Elegant Morally, Excellent Intelectually. Untuk itu, melalui ASEAN Class Program, dilakukan kegiatan antara lain seperti pengenalan ASEAN, pengenalan Masyarakat ASEAN, sharing budaya dengan mahasiswa Thailand, serta berbagi pengalaman dan motivasi dengan mahasiswa yang memiliki pengalaman internasional. Metode pelaksanaan kegiatan meliputi ceramah, sharing, dan diskusi serta dengan adanya pra-test dan post test. Hasil pengabdian menunjukkan adanya peningkatan pengetahuan dan pemahaman peserta program ini tentang ASEAN dan ASEAN Community serta misinformasi tentang negara anggota ASEAN dan pilar ASEAN Community dapat dikoreksi.
\end{abstract}

\section{A B S T R A C T}

This program is aimed to providing knowledge to students of MTs. Muhammadiyah 1 Malang about ASEAN and ASEAN Community. This is based on the lack of information for students about ASEAN because of the limitations of learning materials and information about ASEAN is only as a sub-subject. In addition, the school sees the importance of international insight to realize the vision of Elegant Morally, Excellent Intelectually. Therefore, through the ASEAN Class Program, there are activities such as the introduction of ASEAN and ASEAN community, sharing culture with Thai students, and sharing experiences and motivation with students who have international experience. The methods of activities include lectures, sharing, and discussion as well as pre-test and post-test. The result shows that there is an increased knowledge and understanding of participants about ASEAN and ASEAN Community and misinformation about ASEAN member countries and the ASEAN Community pillar can be corrected.

\footnotetext{
* Corresponding author.

E-mail addresses: najamuddin@umm.ac.id (Najamuddin Khairur Rijal)
} 


\section{Pendahuluan}

Masyarakat ASEAN (ASEAN Community) merupakan perkembangan terkini integrasi negaranegara Asia Tenggara. Masyarakat ASEAN memiliki tiga pilar, yaitu pilar politik-keamanan (ASEAN Political Security Community), pilar ekonomi (ASEAN Economic Community), dan pilar sosial-budaya (ASEAN Sosio-Cultural Community) yang diberlakukan sejak 1 Januari 2016. Dalam upaya mewujudkan integrasi Masyarakat ASEAN tersebut, negara-negara ASEAN membutuhkan kerja keras terutama dalam usaha menumbuhkan rasa kekitaan (we feeling) di antara masyarakatnya sebagai warga ASEAN. ASEAN we feeling sendiri merupakan kesadaran yang lahir pada masing-masing individu bahwa pada dasarnya seluruh rakyat negara-negara anggota ASEAN adalah warga ASEAN (Farhana \& Nufus, 2017).

Dalam konteks Indonesia, pemerintah sesungguhnya memiliki waktu yang cukup panjang untuk melakukan berbagai persiapan dalam menghadapi persaingan kompetitif di era Masyarakat ASEAN (Choiruzzad, 2015). Upaya itu dilakukan Indonesia melalui beragam sosialisasi dan kebijakan. Dalam konteks ekonomi misalnya, guna menyiapkan daya saing menghadapi persaingan ekonomi dengan negara ASEAN lainnya, pemerintah menerbitkan Instruksi Presiden (Inpres) Nomor 11 Tahun 2011 tentang Pelaksanaan Komitmen Cetak Biru Masyarakat Ekonomi ASEAN (MEA) (AEC Center, 2015).

Namun, meskipun telah melakukan berbagai upaya persiapan, disadari bahwa sejatinya pemahaman masyarakat Indonesia tentang Masyarakat ASEAN masih rendah. Hal itu dibuktikan oleh hasil survei Kementerian Luar Negeri pada paruh tahun 2013 mengenai pemahaman masyarakat Indonesia tentang konsep Masyarakat ASEAN menunjukkan tingkat pemahaman yang masih rendah (Syelvia, 2013). Begitu pula hasil penelitian Lembaga Ilmu Pengetahuan Indonesia (LIPI) pada akhir 2015, yakni menjelang pemberlakuan Masyarakat ASEAN, menunjukkan bahwa kesadaran dan tingkat pemahaman masyarakat Indonesia mengenai Masyarakat ASEAN ternyata masih rendah (Khanisa, 2016; Lembaga Ilmu Pengetahuan Indonesia, 2015). Hal yang sama ditemukan pada berbagai survei dan hasil penelitian lainnya (Benny, 2012; Guido Benny \& Kamarulnizam, 2011). Rendahnya pemahaman masyarakat ini menunjukkan bahwa sesungguhnya ide, gagasan, dan wacana Masyarakat ASEAN belum sepenuhnya dipahami masyarakat.

Rendahnya pengetahuan tentang ASEAN dan minimnya kesadaran ber-ASEAN itu juga ditemukan dalam konteks Kota Malang (Rijal, 2017; Rijal, Prasodjo, \& Cahyani, 2020). Berdasarkan hasil penelitian tim pengabdi bersama mahasiswa penempuh mata Kuliah HI Kawasan Asia Tenggara pada tahun 2016 dan 2017 terkait pemahaman pelajar di Malang Raya, ditemukan fakta bahwa pemahaman pelajar tentang Masyarakat ASEAN masih sangat minim. Temuan ini menjadi penting untuk diperhatikan sebab mereka adalah Generasi Emas bangsa Indonesia. Persaingan di era liberalisasi ekonomi, termasuk dalam kerangka Masyarakat ASEAN terutama MEA, ke depan akan semakin kompetitif. Mereka perlu dibekali informasi, pengetahuan dan pemahaman mengenai berbagai peluang sekaligus tantangan Masyarakat ASEAN agar dapat mempersiapkan diri menghadapi kompetisi regional dan global di masa mendatang.

Upaya untuk membangun kesadaran tersebut perlu dimulai dengan mengembangkan pengetahuan dan pemahaman mereka sehingga dapat menumbuhkan kesadaran ber-ASEAN (ASEAN we feeling). Adapun sekolah adalah instrumen kunci yang menjadi wadah transfer pengetahuan tentang ASEAN dan Masyarakat ASEAN kepada pelajar. Dalam konteks ini, MTs. Muhammadiyah 1 Malang menyadari pentingnya pengetahuan mengenai ASEAN dan Masyarakat ASEAN tersebut. Hal ini tidak terlepas pula pada upaya pihak sekolah untuk go international dan memberikan wawasan internasional kepada siswanya.

Namun demikian, berdasarkan diskusi dengan Kepala MTs. Muhammadiyah1 Malang Abdul Wahid, masalah yang dihadapi adalah kurangnya informasi tentang ASEAN dan Masyarakat ASEAN di kalangan siswa/siswi, karena informasi tentang ASEAN dan Masyarakat ASEAN hanya menjadi sub-pembahasan dalam materi mata pelajaran. Kurangnya informasi ini menjadikan pemahaman siswa/siswi tentang ASEAN dan Masyarakat ASEAN masih minim, sementara perkembangan teknologi informasi dan komunikasi berkembang sedemikian cepat yang membawa berbagai informasi yang beragam dan tidak sepenuhnya benar.

Selain itu, pihak sekolah memiliki motto "Elegant Morally, Excellent Intelectually." Salah satu misi untuk mewujudkan motto tersebut adalah "Melakukan kerja sama yang harmonis antar komponen Madrasah dan lembaga kemasyarakatan menuju Madrasah yang unggul dan inovatif." Serta "Membekali siswa dengan pendidikan dan pelatihan life skill agar dapat hidup mandiri dan mengikuti pendidikan lebih lanjut" (MTs. Muhammadiyah 1 Malang, 2018). Guna mewujudkan misi serta motto ini pihak sekolah membutuhkan mitra. Salah satu mitra yang dibutuhkan adalah mitra yang dapat memberikan wawasan internasional, khususnya terkait kawasan Asia Tenggara guna pengembangan "excellent intelectually". Berdasarkan pertimbangan tersebut, maka program pengabdian kepada masyarakat ini diarahkan untuk melakukan kegiatan dalam bentuk ASEAN Class Program. ASEAN Class Program sendiri merupakan 
pembelajaran mingguan di kelas, di luar mata pelajaran utama, yang dirancang untuk memberikan informasi dan pengetahuan tentang ASEAN kepada siswa/siswi.

\section{Metode}

Metode pelaksanaan kegiatan adalah metode ceramah, sharing, dan diskusi untuk memberikan informasi dan pengetahuan tentang ASEAN dan Masyarakat ASEAN serta wawasan internasional kepada siswa/siswi. Metode ini dilakukan dengan tidak bersifat satu arah, melainkan berlangsung dua arah di mana terjadi diskusi dan saling bertukar pandangan dan pengalaman. Hal ini penting dilakukan agar informasi yang disampaikan benar-benar dapat dipahami yang selanjutnya dapat menggugah kesadaran ber-ASEAN siswa/siswi. Selain itu, untuk mengevaluasi pengetahuan siswa/siswi sebelum dan setelah kegiatan dilakukan pra-tes dan post-test.

Pengabdian ini dilakukan pada Oktober-November 2018, terdiri dari lima kali pertemuan. Pengabdian dilakukan di MTs. Muhammadiyah 1 Malang, Jalan Baiduri Sepah No. 27, Kelurahan Tlogomas, Kecamatan Lowokwaru, Kota Malang, Pelaksanaan kegiatan dilakukan dengan sejumlah tahapan, yakni:

Tabel 1. Tahapan Kegiatan

\begin{tabular}{|c|c|}
\hline Tahapan & Kegiatan \\
\hline Persiapan & $\begin{array}{l}\text { - Melakukan kunjungan ke MTs. Muhammadiyah } 1 \text { Malang sebagai bentuk } \\
\text { komunikasi awal program kegiatan. }\end{array}$ \\
\hline Sosialisasi & $\begin{array}{l}\text { - Sosialisasi kepada siswa/siswi dan guru MTs Muhammadiyah } 1 \text { Malang } \\
\text { berkaitan dengan kegiatan yang akan dilaksanakan. } \\
\text { - Menyepakati jadwal pelaksanaan kegiatan dan berbagai persiapan yang } \\
\text { dibutuhkan. }\end{array}$ \\
\hline Pelaksanaan & $\begin{array}{l}\text { - Siswa/siswi diberikan informasi dan pengetahuan tentang ASEAN dan } \\
\text { Masyarakat ASEAN serta wawasan internasional. Sekaligus pemahaman tentang } \\
\text { bekal yang perlu dipersiapkan dalam menghadapi persaingan yang semakin } \\
\text { kompetitif. }\end{array}$ \\
\hline Evaluasi & $\begin{array}{l}\text { - Evaluasi pengetahuan dan pemahaman siswa tentang ASEAN dan Masyarakat } \\
\text { ASEAN melalui kuesioner. } \\
\text { - Evaluasi kegiatan }\end{array}$ \\
\hline
\end{tabular}

\section{Hasil dan pembahasan}

\section{a. Persiapan dan Sosialisasi}

Tahapan awal pelaksanaan program pengabdian masyarakat ini adalah persiapan. Persiapan yang dimaksud untuk menyatukan pandangan dengan mitra serta memahami kebutuhan mitra. Persiapan dimulai dengan melakukan kunjungan kepada mitra sebagai bentuk komunikasi awal rencana program kegiatan pengabdian. Dalam kunjungan ini, tim bertemu dan melakukan komunikasi dengan Kepala MTs. Muhammadiyah 1 Malang Abdul Wahid di Ruang Guru.

Dalam kunjungan ini, tim menyampaikan maksud dan tujuan rencana kegiatan yang akan dilakukan. Rencana ini disambut baik oleh pihak sekolah karena ternyata sejalan dengan visi sekolah untuk mengembangkan sekolah dan siswa/siswi berwawasan internasional. Selanjutnya, pihak mitra menyetujui program pengabdian masyarakat yang akan dilaksanakan, tim pengabdi kembali melakukan kunjungan untuk meminta pihak mitra menandatangani lembar pernyataan persetujuan antara tim pengabdi dan mitra.

Kunjungan selanjutnya adalah tim pengabdi mendiskusikan rencana pelaksanaan kegiatan. Dalam diskusi, disepakati bahwa program ASEAN Class dilaksanakan setiap Sabtu. Alasan pemilihan jadwal tersebut karena pada hari Sabtu, tidak ada kegiatan belajar mengajar sekolah. Melainkan siswa/siswi melakukan aktivitas/kegiatan ekstrakulikuler. Dengan demikian, jadwal program pengabdian dapat berjalan tanpa mengganggu proses pembelajaran.

Selain itu, disepakati pula antara tim pengabdi dan pihak mitra terkait sasaran siswa/siswi yang menjadi peserta. Berdasarkan pertimbangan pihak sekolah, Kelas VIII C disetujui sebagai sasaran program pengabdian ASEAN Class. Alasan pihak sekolah adalah karena kelas tersebut memiliki prestasi akademik yang cenderung lebih baik dibanding Kelas VIII lainnya. Adapun kelas IX tidak disarankan oleh pihak mitra karena sedang dipersiapkan untuk fokus pada Ujian Nasional. Sementara Kelas VII dianggap terlalu dini karena masih tahap transformasi dari Sekolah Dasar. 
Setelah menyepakati jadwal dan kegiatan, selanjutnya sosialisasi kepada siswa/siswi peserta program pengabdian dilakukan oleh pihak sekolah. Sosialisasi dimaksudkan agar siswa/siswi memahami maksud, arah, dan tujuan dari program pengabdian sehingga dapat berpartisipasi dan berkontribusi bagi kesuksesan pelaksanaan kegiatan yang dilakukan. Sosialisasi juga dilakukan kepada guru pengajar agar dapat mendukung realisasi program.

\section{b. Pelaksanaan}

ASEAN Class Program dilaksanakan dalam lima kali pertemuan mulai 13 Oktober sampai dengan 10 November 2018. Dalam lima kali pertemuan tersebut, tim pengabdi dibantu oleh 2 mahasiswa Selain itu, pada pertemuan ketiga hingga kelima, tim juga dibantu oleh mahasiswa asal Thailand dan beberapa mahasiswa yang memiliki pengalaman magang atau pengalaman internasional di berbagai negara ASEAN. Tujuannya adalah mereka diharapkan dapat berbagi kepada siswa/siswi informasi terkait negara-negara ASEAN dan pengalaman mereka. Adapun timeline dan agenda kegiatan yang dilakukan selama program pengabdian berlangsung adalah sebagai berikut:

Tabel 2. Agenda Pertemuan

\begin{tabular}{ll}
\hline Pertemuan & Kegiatan \\
\hline I & Pengenalan dan Pemaparan tentang ASEAN \\
\hline II & Pemaparan tentang Masyarakat ASEAN (ASEAN Community) \\
\hline III & Cultural Sharing dengan Mahasiswa Thailand \\
\hline IV & $\begin{array}{l}\text { Berbagi Pengalaman dengan Kuy Project: A Journey to ASEAN with Coffee (Malaysia, } \\
\text { Singapura, Thailand, Myanmar) }\end{array}$ \\
\hline V & Berbagi Pengalaman dengan Mahasiswa Magang Internasional di Filipina dan Brunei
\end{tabular}

\section{Pertemuan Pertama}

Pertemuan pertama diisi dengan penyampaian materi tentang selayang pandang ASEAN. Penyampaian materi diawali dengan menguji pengetahuan mendasar siswa/siswi tentang ASEAN mulai dari kepanjangan ASEAN, tanggal berdirinya ASEAN, negara pendiri, dan negara-negara anggota. Pada awal materi ini tim pengabdi menemukan adanya misinformasi yang diterima oleh siswa/siswa. Ketika diminta menyebutkan negara-negara anggota ASEAN, hampir semua siswa memasukkan Timor Leste sebagai negara anggota ASEAN. Informasi tersebut pasalnya diterima dari penyampaian guru di kelas.

Dengan misinformasi yang terjadi, tim pengabdi kemudian memberikan penjelasan bahwa Timor Leste memang sejak tahun 2011 telah mengajukan aplikasi keanggotaan untuk bergabung menjadi bagian dari ASEAN. Namun demikian, hingga hari ini keanggotaannya belum disetujui oleh seluruh negara ASEAN dan masih sedang dalam proses telaah terkait kesiapan Timor Leste jika kelak bergabung menjadi anggota ASEAN.

Setelah siswa/siswi dapat menerima informasi yang diberikan, tim pengabdi kemudian melanjutkan dengan memperkenalkan sejarah ASEAN, makna logo ASEAN serta profil singkat dari negaranegara anggota ASEAN. Kegiatan yang berlangsung selama lebih dari jam tersebut dapat diikuti dengan baik dan antusias oleh siswa/siswi. Antusiasme siswa/siswi ditunjukkan dengan keaktifannya mengajukan berbagai pertanyaan, termasuk pertanyaan kritis. Pada pertemuan ini, tim pengabdi memberikan lagu tentang ASEAN untuk dihafalkan oleh siswa/siswi. Lagu ini selanjutnya menjadi lagu yang dinyanyikan setiap awal dan akhir pertemuan. Lagu tersebut dinyanyikan dengan irama lagu "Potong Bebek Angsa". Adapun lirik lagunya adalah sebagai berikut: Ada Indonesia, Singapur, Malaysia/ Brunei, Filipina, Vietnam, Kamboja/Juga Thailand, Laos, Myanmar/Itulah sepuluh negara ASEAN.

\section{Pertemuan Kedua}

Pertemuan ini memperkenalkan mengenai ASEAN Community dengan tiga pilarnya kepada siswa/siswi. Pada pertemuan ini disampaikan tentang apa itu ASEAN Community (Masyarakat ASEAN), kapan dan mengapa diberlakukan, dan penjelasan dari masing-masing tiga pilar ASEAN Community, yaitu pilar politik-keamanan, pilar ekonomi, dan pilar sosial-budaya. Pada pertemuan kedua ini, tim pengabdi kembali menemukan adanya misinformasi di kalangan siswa/siswi. Menurut mereka, pilar ASEAN Community ada empat, pilar keempat adalah pendidikan. Pemahaman tersebut diperoleh dari penjelasan guru.

Oleh karena menurut tim ada misinformasi, tim pengabdi kemudian memberikan penjelasan bahwa pendidikan bukanlah pilar keempat dari ASEAN Community. Melainkan pendidikan merupakan satu bagian atau karakteristik utama yang ada di dalam pilar sosial-budaya yang bertujuan untuk mewujudkan 
masyarakat ASEAN yang caring and sharing. Penjelasan tim pengabdi akhirnya dapat diterima oleh siswa/siswi.

\section{Pertemuan Ketiga}

Pada pertemuan ini tim pengabdi menghadirkan dua orang mahasiswa asal Thailand yang kuliah di UMM. Keduanya berbagi informasi tentang Thailand, mulai dari sejarah, kehidupan sosial budaya masyarakat, serta fakta-fakta menarik tentang Negeri Gajah Putih tersebut. Selama pertemuan, siswa/siswi sangat aktif dan mahasiswa Thailand sangat interaktif. Hampir semua siswa/siswi mengajukan berbagai pertanyaan tentang Thailand. Adapun mahasiswa Thailand menjawab seluruh pertanyaan dengan jelas. Kedua belah pihak dapat berkomunikasi dengan baik karena kedua mahasiswa Thailand yang dihadirkan fasih berbahasa Indonesia (Melayu) sehingga komunikasi dua arah dapat berlangsung interaktif dan semua penjelasan dapat dipahami oleh siswa/siswi.

Setelah sesi sharing dan diskusi, selanjutnya siswa/siswi diajak untuk belajar bahasa Thailand. Mahasiswa Thailand menuliskan di papan tulis tentang bahasa Thailand (lisan dan tulisan) dari berbagai sapaan (saya, kami, dia, kita, kami, laki-laki, perempuan, dan lainnya), ucapan selamat (pagi, siang, sore, malam, dan lainnya), serta bahasa Thailand dari berbagai benda atau hal-hal dasar lainnya. Pada bagian akhir, semua siswa/siswi dituliskan namanya dengan menggunakan huruf Thailand.

Menurut tim pengabdi, pembelajaran semacam ini menjadi penting dan menarik, di mana siswa/siswi diajak untuk berinteraksi langsung dengan masyarakat dari salah satu negara ASEAN. Sehingga mereka dapat memperoleh informasi dari sumber pertama sekaligus belajar langsung crossculture communication. Sehingga, diharapkan siswa/siswi memiliki wawasan internasional yang pada muaranya diharapkan dapat membangun kesadaran ber-ASEAN (ASEAN We Feeling).

\section{Pertemuan Keempat}

Pada pertemuan keempat tim pengabdi mengundang dua orang mahasiswa yang memiliki pengalaman keliling Malaysia, Singapura, Thailand, dan Myanmar. Sembari berkeliling, keduanya melakukan diplomasi kopi dengan membagi-bagikan sebungkus kopi yang dikemas khusus kepada masyarakat yang ditemuinya. Tujuannya adalah untuk mengkampanyekan tentang persatuan dalam keberagaman di ASEAN. Keduanya membentuk komunitas yang disebut Kuy Project. Dikutip dari Instagram Kuy Project, Kuy Project sendiri adalah proyek kesadaran sosial yang bertujuan untuk mempromosikan kawasan Asia Tenggara melalui pemuda dan budaya. Kuy Project fokus pada generasi muda di Asia Tenggara yang diharapkan dapat mengetahui dan punya kepedulian terkait kawasan.

Dalam kesempatan tersebut, keduanya menceritakan berbagai kisah pengalamannya mengelilingi beberapa negara Asia Tenggara dan bagaimana mereka melakukan diplomasi dengan menggunakan sebungkus kopi. Siswa/siswi sangat antusias dengan kisah yang dibagikan oleh Kuy Project, terutama ketika bercerita tentang negara Myanmar. Hal ini setidaknya menunjukkan bahwa siswa/siswi sasaran program ASEAN Class punya rasa ingin tahu yang besar dan punya sense of international untuk mengetahui dan mengenali berbagai negara di kawasan Asia Tenggara. Pada akhirnya, mereka diharapkan dapat memiliki kesadaran sebagai bagian dari masyarakat ASEAN yang punya kontribusi yang besar.

\section{Pertemuan Kelima}

Pertemuan terakhir ini tim peneliti menghadirkan empat orang mahasiswa yang memiliki pengalaman magang internasional di Kedutaan Besar Republik Indonesia (KBRI) Filipina dan Brunei Darussalam. Keempat mahasiswa tersebut berbagai informasi tentang fakta-fakta menarik dari Brunei Darussalam dan Filipina serta pengalaman mereka selama magang satu bulan di negara tersebut. Tentang Brunei, misalnya, berbagi tentang karakter masyarakat Brunei dan bagaimana masyarakat Brunei memberikan penghormatan yang besar kepada Sultan. Kemudian, tentang gambaran kehidupan sosial di Brunei yang masyarakatnya makmur dan sejahtera. Tentang Filipina, misalnya bercerita tentang sulitnya menemukan makanan halal di Manila karena sebagian besar penduduk beragama Kristen Protestan serta bagaimana pandangan sinis masyarakat Manila terhadap orang Islam, terutama perempuan yang bercadar.

Selama pertemuan, seluruh siswa/siswi menyimak dengan antusias dan mengajukan berbagai pertanyaan terkait berbagai hal yang mereka ingin ketahui tentang Filipina dan Brunei. Selain itu, keempat mahasiswa tersebut juga berbagi tips untuk menyiapkan diri menghadapi berbagai tantangan di masa mendatang.

\section{c. Evaluasi}

Evaluasi hasil kegiatan ASEAN Class Program dilakukan kepada siswa/siswi melalui pra-test dan post-test. Pra-test dilakukan pada pertemuan pertama untuk mengetahui pengetahuan siswa/siswi 
sasaran program terkait pengetahuan dasar tentang ASEAN dan Masyarakat ASEAN sebelum kegiatan dilakukan lebih lanjut. Kemudian pada pertemuan akhir dilakukan post-test dengan 10 pertanyaan yang sama dengan pra-test. Tujuannya untuk mengetahui perkembangan pengetahuan siswa/siswi setelah kegiatan dilaksanakan. Hasil pra-test dan post-test ditampilkan dalam tabel di bawah ini,

Tabel 3. Hasil Pra-Test dan Post-Test

\begin{tabular}{llll}
\hline Nomor & Pertanyaan & Pra-Test (\%) & Post-Test (\%) \\
\hline $\mathbf{1}$ & Kepanjangan ASEAN & 58,82 & 92,31 \\
\hline $\mathbf{2}$ & Kapan ASEAN didirikan & 76,47 & 100 \\
\hline $\mathbf{3}$ & Negara pendiri ASEAN & 82,35 & 86,92 \\
\hline $\mathbf{4}$ & Negara anggota ASEAN & 5,88 & 100 \\
\hline $\mathbf{5}$ & Lokasi sekretariat ASEAN & 70,59 & 92,31 \\
\hline $\mathbf{6}$ & Semboyan ASEAN & 41,18 & 100 \\
\hline $\mathbf{7}$ & Ketua ASEAN & 0 & 46,15 \\
\hline $\mathbf{8}$ & ASEAN Community & 0 & 46,15 \\
\hline $\mathbf{9}$ & Pilar ASEAN Community & 0 & 76,92 \\
\hline $\mathbf{1 0}$ & Kapan pemberlakuan ASEAN Community & 0 & 15,38 \\
\hline
\end{tabular}

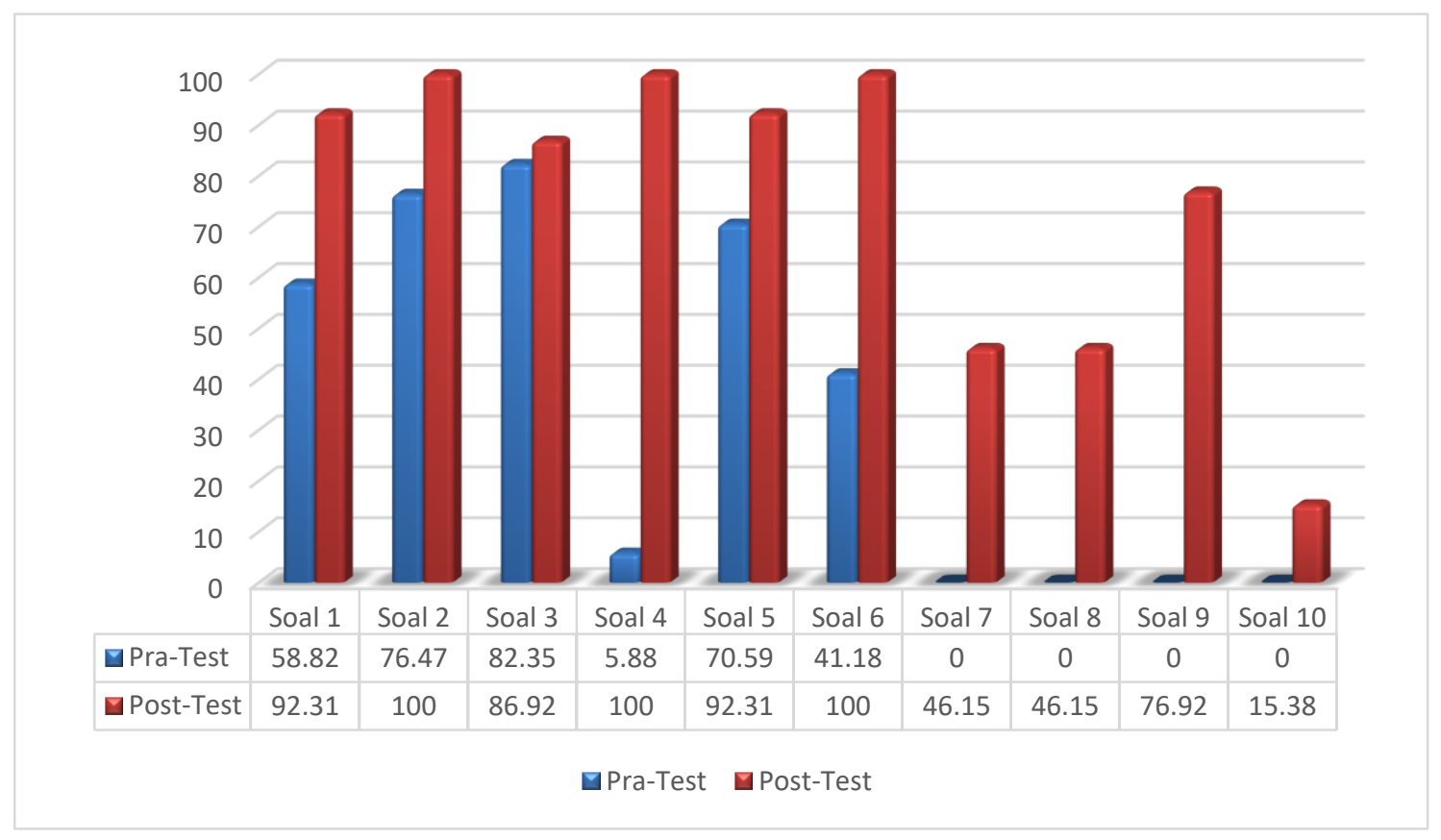

Gambar 1. Bagan Perbandingan Hasil Pra-Test dan Post-Test

\section{Pembahasan}

Perbandingan hasil pra-test dan post-test yang ditampilkan pada tabel dan bagan di atas menunjukkan bahwa terjadi peningkatan pengetahuan siswa/siswi tentang ASEAN dan ASEAN Community. Hal itu dapat dilihat pada peningkatan signifikan persentase beberapa pertanyaan yang dijawab dengan benar oleh peserta,

Pertanyaan tentang kepanjangan ASEAN, misalnya, sebelum program pengabdian dilakukan ditemukan fakta bahwa hanya 58,82 \% yang mampu menjawab dengan benar Association of Southeast Asian Nations sebagai kepanjangan organisasi regional yang didirikan pada 8 Agustus 1967 itu. Pada hasil post-tes terjadi peningkatan menjadi $92,31 \%$ peserta yang mampu memberikan jawaban benar.

Selanjutnya pada pertanyaan negara anggota ASEAN, ditemukan hasil bahwa hanya 5,88 \% peserta yang mampu menjawab dengan benar negara anggota ASEAN. Sisanya, sebagian besar peserta menjawab bahwa anggota ASEAN sebanyak 11 negara. Negara kesebelas yang disebut sebagai anggota ASEAN adalah Timor Leste. Padahal sebagaimana dipahami bahwa ASEAN hanya terdiri dari sepuluh negara anggota. Adapun Timor Leste belum masuk dalam keanggotaan ASEAN. 
Dikutip dari buku ASEAN Selayang Pandang yang diterbitkan oleh Kementerian Luar Negeri RI, secara geografis Timor Leste terletak di wilayah Asia Tenggara. Namun demikian, dalam konteks keanggotaan ASEAN, negara yang melepaskan diri dari Indonesia pada tahun 2002 itu belum menjadi anggota ASEAN. Timor Leste telah mendaftarkan diri sebagai anggota ASEAN sejak tahun 2011. Namun ikhwal keanggotaannya masih dalam pembahasan kesepuluh negara anggota ASEAN (Direktorat Jenderal Kerja Sama ASEAN, 2015, 2016). Adapun Indonesia berkomitmen untuk terus memberikan dukungan agar Timor Leste dapat diterima sebagai anggota ASEAN (Liland, 2019).

Berdasarkan diskusi dengan peserta program, informasi tentang keanggotaan Timor Leste di ASEAN diperoleh dari penjelasan guru. Adapun guru memberikan penjelasan berdasarkan buku Lembar Kerja Siswa (LKS). Hal ini menggambarkan bahwa ada misinformasi terkait keanggotaan ASEAN yang selama ini diajarkan di sekolah. Melalui kegiatan ASEAN Class Program yang telah dilakukan, misinformasi ini dapat dikoreksi dan dapat diterima oleh peserta.

Selanjutnya pertanyaan tentang semboyan ASEAN, awalnya hanya 41,18 \% peserta yang mampu memberikan jawaban bahwa semboyan ASEAN adalah “One Vision, One Identity, One Community." Setelah tim pengabdi mengonfirmasi jawaban peserta, ternyata peserta yang mampu menjawab sebenarnya tidak mengetahui jawabannya. Mereka hanya melihat dan mengutip dari spanduk kegiatan pengabdian yang dipasang di depan kelas. Namun demikian, setelah memberikan penjelasan tentang makna semboyan ASEAN, hasil post-test menunjukkan seluruh peserta (100 \%) mampu memberikan jawaban yang sesuai.

Selain itu, misinformasi juga terjadi pada pilar ASEAN Community. Pada pra-test tidak ada peserta yang memberikan jawaban benar bahwa ASEAN Community terdiri dari tiga pilar, yakni pilar politikkeamanan (ASEAN Political Security Community/APSC), pilar ekonomi (ASEAN Economic Community/AEC), dan pilar sosial-budaya (ASEAN Socio-Cultural Community/ASCC). Sebagian besar jawaban sejatinya menjawab dengan benar bahwa pilar ASEAN Community ada tiga. Namun ketika diminta menyebutkan, sebagian besar memasukkan pilar pendidikan sebagai salah satu pilar ASEAN Community, selain pilar sosial-budaya dan ekonomi.

Jawaban bahwa pendidikan merupakan salah satu pilar ASEAN Community adalah sebuah kesalahan informasi. Celakanya menurut pengakuan siswa/siswi, informasi tersebut diperoleh dari penjelasan guru di kelas. Untuk itu, tim pengabdi berusaha memberikan koreksi dan penjelasan bahwa pendidikan bukan merupakan pilar ASEAN Community, melainkan pendidikan merupakan salah satu poin dalam pilar sosial budaya.

Lebih lanjut, berdasarkan paparan di atas, kegiatan semacam ini menjadi penting untuk meluruskan berbagai informasi yang keliru tentang ASEAN. Hal itu relevan untuk mendukung salah satu target dalam ASEAN Community tentang penguatan pemahaman mengenai ASEAN. Untuk mewujudkan hal tersebut, ASEAN sendiri telah menyusun ASEAN Curriculum Sourcebook sebagai pedoman bagi lembaga pendidikan di negara-negara anggota ASEAN untuk menyebarluaskan pengetahuan mengenai ASEAN di kalangan siswa (Direktorat Jenderal Kerja Sama ASEAN, 2017).

\section{Simpulan dan saran}

Pelaksanaan kegiatan pengabdian kepada masyarakat ini dapat berjalan dengan baik dan sesuai dengan hasil yang diharapkan. Hal itu ditandai dengan antusiasme peserta dalam mempelajari dan mengenai ASEAN dan negara-negara Asia Tenggara. Kegiatan ini dapat dikatakan berhasil karena terjadi peningkatan pengetahuan siswa/siswi tentang ASEAN dan ASEAN Community yang dapat dilihat dari hasil tes. Selain itu, misinformasi tentang ASEAN yang terjadi sebagaimana telah dibahas di atas dapat diperbaiki dan diterima dengan baik oleh seluruh siswa/siswi.

Adapun potret permasalahan lain yang ditemukan oleh tim pengabdi selama kegiatan adalah adanya misinformasi terkait negara anggota ASEAN dan pilar ASEAN Community. Hal ini berarti program semacam ini perlu dilanjutkan dan dilakukan di berbagai sekolah guna membangun kesadaran ber-ASEAN dan memasyarakatkan ASEAN di kalangan pelajar. Diperlukan pendampingan, sosialisasi, seminar, atau hal lain yang sasarannya kepada para guru agar memiliki pengetahuan yang komprehensif tentang ASEAN sehingga permasalahan terkait misinformasi tersebut tidak lagi terjadi.

\section{Daftar Rujukan}

AEC Center. (2015). Persiapan Indonesia Menyambut AEC 2015. Retrieved July 19, 2018, from http://aeccenter.kemendag.go.id/tentang-aec-2015/persiapan-indonesia/

Benny, G. (2012). Public Perception in Indonesia on the Obstacles for Establishing the ASEAN Community. International Journal on Social Science Economic \& Arts, 2(3), 30-37. 
Choiruzzad, S. A. B. (2015). ASEAN di Persimpangan Sejarah. Jakarta: Yayasan Pustaka Obor Indonesia.

Direktorat Jenderal Kerja Sama ASEAN. (2015). ASEAN Selayang Pandang (21st ed.). Jakarta: Sekretariat Direktorat Jenderal Kerja Sama ASEAN.

Direktorat Jenderal Kerja Sama ASEAN. (2016). Ayo Kenali ASEAN. Jakarta: Sekretariat Direktorat Jenderal Kerja Sama ASEAN.

Direktorat Jenderal Kerja Sama ASEAN. (2017). ASEAN Selayang Pandang (22nd ed.). Jakarta: Sekretariat Direktorat Jenderal Kerja Sama ASEAN.

Farhana, F., \& Nufus, H. (2017). Kita dan ASEAN: Ayo Berlari Bersama. Yogyakarta: Pustaka Pelajar dan LIPI.

Guido Benny, \& Kamarulnizam, A. (2011). Indonesian Perceptions and Attitudes toward the ASEAN Community. Journal of Current Southeast Asian Affairs, 30(1), 46-51.

Khanisa. (2016). Strategi Peningkatan Pemahaman Masyarakat tentang Masyarakat Ekonomi ASEAN. Jurnal Penelitian Politik, 13(1), 105-118.

Lembaga Ilmu Pengetahuan Indonesia. (2015). Pemahaman terhadap MEA Masih Rendah. Retrieved October 17, 2017, from http://lipi.go.id/berita/single/Pemahaman-terhadap-MEA-MasihRendah/10474

Liland, Z. (2019). RI akan Terus Dorong Timor Leste Jadi Anggota ASEAN. Retrieved September 23, 2019, from https://news.detik.com/berita/d-4552987/ri-akan-terus-dorong-timor-leste-jadi-anggotaasean $\% 0 \mathrm{D}$

MTs. Muhammadiyah 1 Malang. (2018). Profil Sekolah. Retrieved December 5, 2018, from https://mtsmuh1malang.sch.id/profil.php

Rijal, N. K. (2017). Tantangan Implementasi ASEAN Community: Kasus di Kota Malang. Jurnal Insignia, $4(1), 53-67$.

Rijal, N. K., Prasodjo, H., \& Cahyani, R. A. T. (2020). Asean Class Program Bagi Guru di SMA Diponegoro Tumpang, Kabupaten Malang, Jawa Timur. J-ABDIPAMAS (Jurnal Pengabdian Kepada Masyarakat), 4(1), 135-141.

Syelvia, Y. (2013). Pemahaman Masyarakat tentang ASEAN Community Masih Rendah. Retrieved October 17, 2017, from http://international.sindonews.com/read/752223/40/pemahaman-masyarakattentang-komunitas-asean-masih-rendah-1371734723 